\title{
Discovery of Eurytrema Eggs in Sediment from a Colonial Period Latrine in Taiwan
}

\author{
Hui-Yuan Yeh ${ }^{1}$, Chieh-fu Jeff Cheng'², ChingJung Huang ${ }^{3}$, Xiaoya Zhan', Weng Kin Wong ${ }^{1,4}$, Piers D. Mitchell5,* \\ 'School of Humanities, Nanyang Technological University, 14 Nanyang Drive, 637332 Singapore; ${ }^{2}$ Department of Archaeology, Boston University, \\ 675 Commonwealth Avenue, Boston, MA 02215, USA; 3institute of Archaeology, National Cheng Kung University, No. 1, University Road, Tainan \\ City, 70101, Taiwan; “Biomedicine Programme, School of Health Sciences, Universiti Sains Malaysia, 16150 Kubang Kerian, Kelantan, Malaysia; \\ ${ }^{5}$ Department of Archaeology, University of Cambridge, The Henry Wellcome Building, Fitzwilliam Street, Cambridge CB2 1QH, UK
}

\begin{abstract}
In this study we take a closer look at the diseases that afflicted Japanese police officers who were stationed in a remote mountainous region of Taiwan from 1921 to 1944. Samples were taken from the latrine at the Huabanuo police outpost, and analyzed for the eggs of intestinal parasites, using microscopy and ELISA. The eggs of Eurytrema sp., (possibly E. pancreaticum), whipworm and roundworm were shown to be present. True infection with Eurytrema would indicate that the policemen ate uncooked grasshoppers and crickets infected with the parasite. However, false parasitism might also occur if the policemen ate the uncooked intestines of infected cattle, and the Eurytrema eggs passed through the human intestines. These findings provide an insight into the diet and health of the Japanese colonists in Taiwan nearly a century ago.
\end{abstract}

Key words: Eurytrema, colonial period latrine, Batongguan Trail, Taiwan

In the late 19th century, Taiwan was ceded to Japan by the Qing Empire as part of the conclusion of the first Sino-Japanese War by the Treaty of Shimonoseki. The island entered a new era as Japan became its ruler in 1895, and it became the first colony acquired since the Meiji Restoration of Japan in 1868 [1]. Under Japanese rule policemen were in charge of supressing criticism against the Japanese, and they also maintained economic control, especially during the Sino-Japanese War and World War II [2]. Some of the police outposts were built specifically to access the rural mountainous regions, in order to ensure control in every part of the island [3].

The Batongguan Trail (known as Batongguan gudao) (Fig. 1) traverses the Central Mountain Range of Taiwan. Forty-four police outposts were constructed along the trail [4-6]. Police officers and their families were billeted at the outposts, notwithstanding their extremely rural location $[7,8]$. Knowing the lifestyles of these Japanese officers and their families will help our understanding of Japanese colonization in the remote ar-

- Received 4 July 2019, revised 27 August 2019, accepted 30 September 2019

*Corresponding author (pdm39@cam.ac.uk)

(c) 2019. Korean Society for Parasitology and Tropical Medicine

This is an Open Access article distributed under the terms of the Creative Commons Attribution Non-Commercial License (http://creativecommons.org/licenses/by-nc/4.0) which permits unrestricted non-commercial use, distribution, and reproduction in any

medium, provided the original work is properly cited. eas of Taiwan.

Nearly a century later, little is known about the health consequences of this migration for the Japanese personnel who were posted to these new regions. The aim of this research is to investigate the intestinal parasitic diseases experienced by the Japanese colonists working in the police service in the mountainous areas of Taiwan, from the analysis of the latrine of a colonial police outpost.

The Huabanuo police outpost on the Batongguan Trail was in use from AD 1921-1944. We chose this police outpost for the study as it is the best-preserved in the Batongguan region. The police outpost was surveyed, and when the cesspool was excavated sediment was taken for parasite analysis. The sediment was then sent to the University of Cambridge Ancient Parasites Laboratory for analysis.

The sample of cesspool sediment was air dried. A subsample weighing $0.2 \mathrm{~g}$ underwent disaggregation using $5 \mathrm{ml}$ of $0.5 \%$ aqueous solution of trisodium phosphate [9]. It took about one hour until a suspension was obtained. The sample was then passed through a series of microsieves to separate parasite eggs from larger soil particles $[9,10]$. Most eggs of intestinal worms that parasitize humans in Asia have a dimension of about $10 \mu \mathrm{m}$ to $150 \mu \mathrm{m}$. Therefore, the samples were passed through microsieves with a mesh sizes of $300 \mu \mathrm{m}$ and 160 

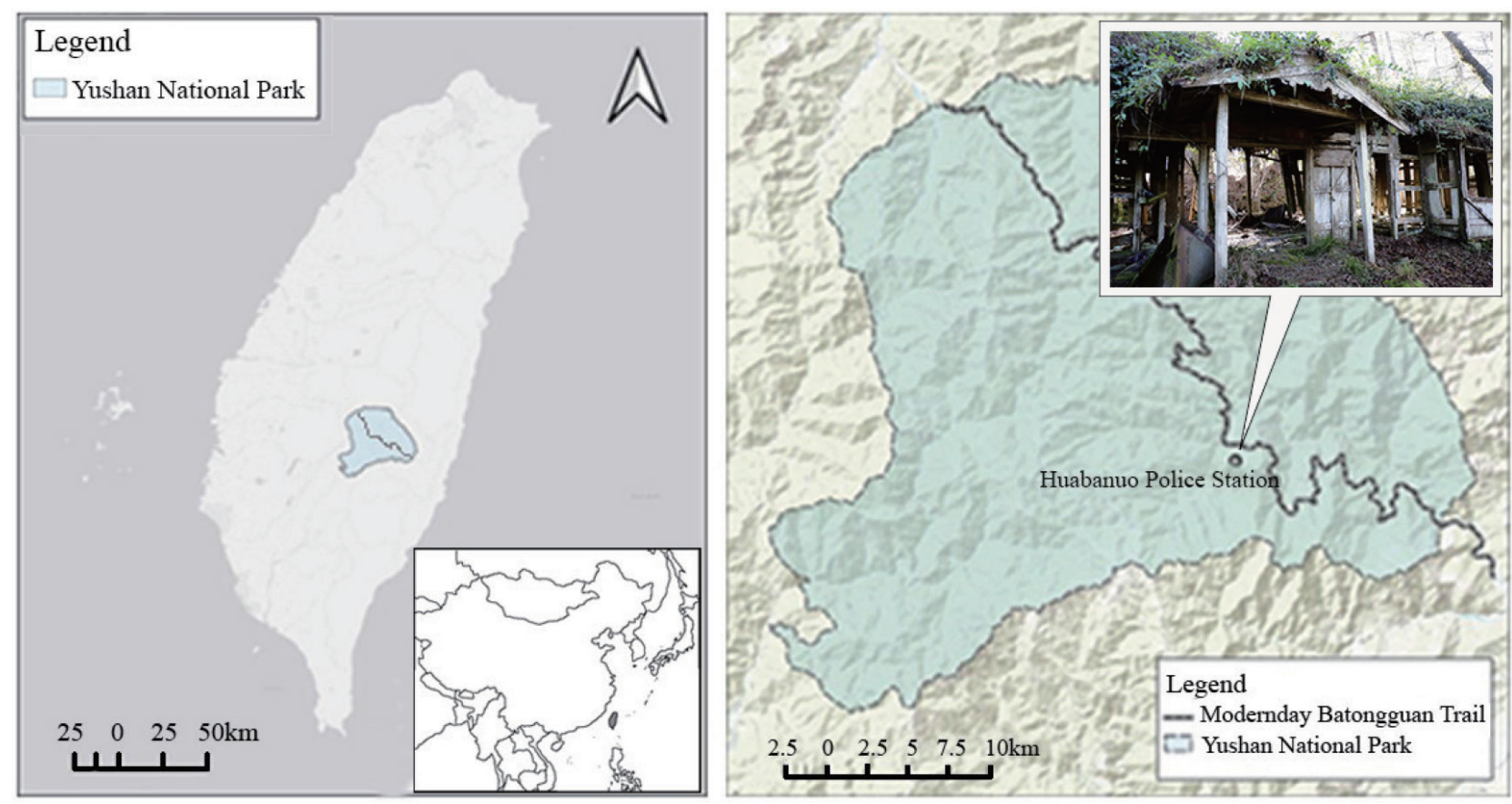

Fig. 1. The location of the police outpost analyzed in this study. The plan of the police outpost with location of the toilet is given in online supplementary material (Supplementary Fig. 1).

$\mu \mathrm{m}$, and the sediment collected in the tray at the base of the stack was analysed. After concentrating the sample using centrifugation, it was mixed with glycerol and mounted on slides. Digital light microscopy at $\mathrm{x} 400$ magnification was used for visualisation. We used an Olympus BX40F microscope (Tokyo, Japan) with GXCAM-9 digital camera (Suffolk, UK) and GXCapture version 7.1.0.0 software by GT vision (Suffolk, UK). The identification of the parasite eggs was based on their morphology, dimensions, colour and special characteristics, in accordance with standard parasitological sources [11,12]. Egg counts per gram of soil can be determined using a number of methods [13]. As we fully examine a $0.2 \mathrm{~g}$ subsample, the number of eggs observed was multiplied by 5 to determine the number per gram of latrine sediment.

The cesspool sample was also tested for the protozoa Entamoeba histolytica, Giardia duodenalis, and Cryptosporidium parvum with ELISA kits made by Techlab ${ }^{\odot}$ (Blacksburg, Virginia, USA). Antigenic proteins from these protozoa display reasonable preservation in archaeological samples [14]. The sediment samples were distributed in equal aliquots to each test well. A positive result is determined by measuring the optical density at $450 \mathrm{~nm}$ on a microplate ELISA reader. We used a BioTek Synergy HT Multi-Mode Microplate Reader (Winooski, Vermont, USA).
Microscopy of the sediment identified the eggs of Ascaris sp. at 10 eggs per gram of sediment, Trichuris sp. at 10 eggs per gram, and Eurytrema sp. at 100 eggs per gram (Fig. 2). The whipworm eggs were identified by their lemon shape, brown smooth surface, the location of polar plugs, and dimensions of 50-54 $\mu \mathrm{m}$ long by 20-23 $\mu \mathrm{m}$ wide. The roundworm eggs were identified by their oval shape, brown mammillated surface, and dimensions of 45-75 $\mu \mathrm{m}$ long by 35-50 $\mu \mathrm{m}$ wide $[11,12]$. The morphology of Eurytrema sp. eggs were distinctive, as they were oval in shape, operculated, and have a dimension of 44-50 $\mu \mathrm{m}$ in length and 27-33 $\mu \mathrm{m}$ in width [15]. ELISA analysis of the sample for the protozoa Entamoeba histolytica, Giardia duodenalis, and Cryptosporidium parnum was negative.

The lifestyle and diet of the Japanese colonial officers and their families during the early twentieth century in Batongguan can be examined through the parasitic analysis of the sediment from the cesspool in the police outpost on the Batongguan Trail. Whipworm and roundworm eggs were present at low concentrations in this cesspool, indicating that the colonists were probably infected with low numbers of whipworm and roundworm, often spread by eating food contaminated by human faeces. These species have been found in archaeological samples from past populations in East Asia [16-20]. However, the finding of Eurytrema sp. in the cesspool is partic- 

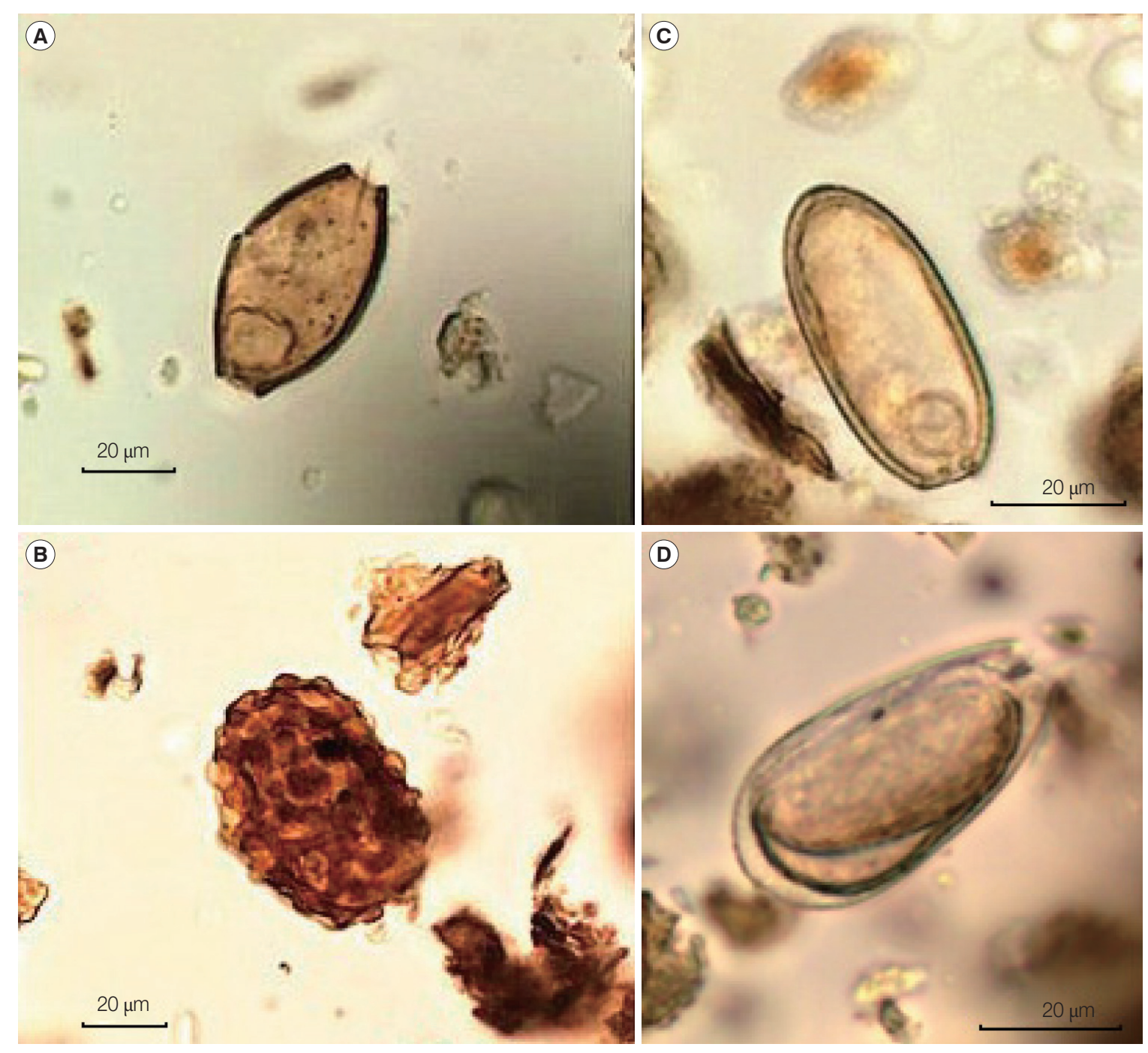

Fig. 2. Parasite eggs identified in the cesspool at the Japanese police outpost on the Batongguan Trail. Egg (A) whipworm; egg (B) roundworm; egg (C) Eurytrema sp. without embryo; egg (D) Eurytrema sp. with embryo.

ularly interesting.

Eurytrema is a genus of trematode that generally infects vertebrate animals, and occasionally infects humans. Eurytrema sp. eggs were identified at a concentration of 100 eggs per gram, which was a higher concentration than whipworm and roundworm eggs. In contrast to whipworm and roundworm, Eurytrema sp. requires snails and grasshoppers (Conocephalus sp.) or crickets (Oecanthus sp.) as intermediate hosts to complete its life cycle. The infection is transmitted when these insect hosts are eaten by the definitive hosts such as cattle, camels, pigs or humans [21]. The most common species to infect humans in East Asia is Eurytrema pancreaticum [11,21]. The adult flukes of Eurytrema pancreaticum are found in the pancre- atic ducts, and occasionally in the bile ducts and small intestines [21]. Several human Eurytrema pancreaticum infections have been reported in modern Japan [15], but never before in archaeological samples from East Asia [16-20]. In China, infection occurs less frequently among camels and monkeys $[15,22]$ and the majority of cases occur among Asian cattle [23].

Widespread parasitic infections were seen in cattle in Hiroshima, Shikoku, and Kyushu in the last 2 centuries. In the late 19th century, the prevalence of parasitic infection by various species in Japanese beef was 19.5-22.9\% in a slaughter house located in Tokyo prefecture [24]. Before 1945, Eurytrema sp. were reported in sheep and/or cattle-raising farms across the 
Far East, including mainland China [25], Taiwan [26], and Japan [27-30]. There were at least 6 species of parasites that have been reported, namely, E. pancreaticum, E. coelomaticum, E. dajii, E. ovis, E. parrum and E. tonkinense [31-34]. The presence of this parasite in Taiwan was also reported by Japanese researcher as one of the possible etiologies for urocystitis haemorrhagica of Formosa native cattle in 1928 [26].

Finding the eggs in this latrine may indicate a Eurytrema sp. infection in humans, or alternatively false parasitism. It is possible the policeman and his family ate uncooked cattle intestines that contained Eurytrema sp. eggs, and so may they passed through them unchanged in their own faeces. However, if this is a case of true parasitism, this would show that humans became infected after they ate grasshoppers containing metacercariae [15]. It is unclear if the police contracted the $\mathrm{Eu}$ rytrema in Japan before they migrated, or contracted it in Taiwan. Either way, the parasite findings from the cesspool in the police outpost at the Batongguan Trail offer a fascinating insight into the lives of those in the Japanese police service posted to the remote mountains of Taiwan nearly a century ago.

\section{ACKNOWLEDGMENTS}

We are grateful to the veterinary parasitologists working in Taiwan who we asked to give a second opinion on these eggs, confirming that they were Eurytrema sp.

\section{CONFLICT OF INTEREST}

We have no conflict of interest related to this study.

\section{REFERENCES}

1. Liao PH, Wang DW. Taiwan Under Japanese Colonial Rule, 1895-1945: History, Culture, Memory. New York, USA. Columbia University Press. 2006.

2. Li CX. The Police System in Taiwan Under Japanese Colonialism. Taipei, Taiwan. National Taiwan University. 1996.

3. Tsai MC. The Gaze of Colonial Police on the Colonized: Discourse on the Colonial Police, Social Control and Space Reform in Colonial Taiwan. Tainan, Taiwan. National Cheng Kung University. 2008 (in Chinese).

4. Lin YH. 82, 145 Meters: Historical Stories of the Eastern Section of the Japanese Batongguan Trail. Nantou, Taiwan. Yushan National Park Adminstration Office. 2005 (in Chinese).

5. Yang NJ, Wang SE. Research Report on the Western Section of the Batongguan Historical Trail in Yushan National Park. Nan- tou, Taiwan. Yushan National Park Administration Office. 1987 (in Chinese).

6. Yang NJ, Wang SE. Research Report on the Eastern Section of the Batongguan Historical Trail in Yushan National Park. Nantou, Taiwan. Yushan National Park Adminstration Office. 1989 (in Chinese).

7. Lin YH. Police Chūzaisyo (Substation at Aboriginal Area) in Colonial Taiwan. Taipei, Taiwan. National Taiwan Museum. 2009 (in Chinese).

8. Lin YH. The fingertips of the governor-general: an approach of Japanese police Chuzaisyo (substation at aboriginal area) from the Wushe (Musha) incident. Taiw Nat Sci 2011; 30: 10-19 (in Chinese).

9. Anastasiou E, Mitchell PD. Simplifying the process of extracting intestinal parasite eggs from archaeological sediment samples: a comparative study of the efficacy of widely-used disaggregation techniques. Int J Paleopathol 2013; 3: 204-207.

10. Bouchet F, Harter S, Le Bailly M. The state of the art of paleoparasitological research in the Old World. Mem Inst Oswaldo Cruz 2003; 98: 95-101.

11. Garcia LS. Diagnostic Medical Parasitology. 6th ed. Washington, USA. ASM Press. 2016.

12. Gunn A, Pitt SJ. Parasitology: An Integrated Approach. 1st ed. Chichester, UK. John Wiley \& Sons. 2012.

13. Reinhard KJ, Confalonieri UE, Herrmann B, Ferreira LF, de Araujo AJG. Recovery of parasite remains from coprolites and latrines: aspects of paleoparasitological technique. Homo 1986; 37: 217-239.

14. Le Bailly M, Maicher C, Dufour B. Archaeological occurrences and historical review of the human amoeba, Entamoeba histolytica, over the past 6000 years. Inf Gen Evol 2016; 42: 34-40.

15. Ishii Y, Koga M, Fujino T, Higo H, Ishibashi J, Oka K, Saito S. Human infection with the pancreas fluke, Eurytrema pancreaticum. Am J Trop Med Hyg 1983; 32: 1019-1022.

16. Yeh HY, Mitchell PD. Ancient human parasites in ethnic Chinese populations. Korean J Parasitol 2016; 54: 565-572.

17. Yeh HY, Chen YP, Mitchell PD. Human intestinal parasites from the Wushantou Site in neolithic period Taiwan (800-1 BC). J Isl Coast Archaeol 2016; 11: 425-434.

18. Yeh HY, Mao R, Wang H, Qi W, Mitchell PD. Early evidence for travel with infectious diseases along the Silk Road: intestinal parasites from 2000 year-old personal hygiene sticks in a latrine at Xuanquanzhi relay station in China. J Arch Sci Rep 2016; 9: 758764.

19. Seo M, Shin DH. Parasitism, cesspits and sanitation in East Asian countries prior to modernisation. In Mitchell PD ed, Sanitation, Latrines and Intestinal Parasites in Past Populations. Farnham, UK. Ashgate. 2015, pp 149-164.

20. Matsui A, Kanehara M, Kanehara M. Palaeoparasitology in Japan: discovery of toilet features. Mem Inst Oswaldo Cruz 2003; 98: 127-136.

21. Zajac AM, Conboy GA. Veterinary Clinical Parasitology. Chichester, UK. John Wiley \& Sons. 2012. 
22. Looss A, Cuffey E. Some parasites in the museum of the School of Tropical Medicine, Liverpool: A case of distomiasis of the liver and the rectum. Ann Trop Med Parasitol 1907; 1: 122-157.

23. Roy B, Tandon V. Seasonal prevalence of some zoonotic trematode infections in cattle and pigs in the north-east montane zone in India. Vet Parasitol 1992; 41: 69-76.

24. Takanori M. Development of pancreatic fluke. Res Parasitol Jap 1964; 4: 449-456 (in Japanese).

25. Mönnig HO. Veterinary Helminthology and Entomology. 3rd ed. London, UK. Bailliere, Tindall and Cox. 1949.

26. Miyamoto T. Urocystitis haemorrhagica of native cattle in Formosa. J Vet Med Sci 1928; 7: 190-206.

27. Miki Y. Notes on the embryonic development of Dicrocoelium dendriticum and Eurytrema pancreaticum. J Okayama Med Assoc 1937; 49: 1425-1476.

28. Itagaki S. The fate of parasitic nematodes in the appendix after appendix ligation and appendectomy. J Vet Med Sci 1929; 42: 22-41 (in Japanese).

29. Jirou $\mathrm{KH}$. The minutes of 14 th infectious disease association meeting. J Microbiol 1913; 371-395.

30. Takegami K. A few supplements on livestock parasitic insects. Cent Med J 1915; 28: 309-314.

31. Tang CC. Studies on the life history of Eurytrema pancreaticum Janson, 1889. J Parasitol 1950; 36: 559-573.

32. Bhalerao G. A contribution to the knowledge of the trematode parasites of the food mammals of Rangoon. Ann Trop Med Parasitol 1924; 18: 139-156.

33. Tubangui MA. Metazoan parasites of Philippine domesticated animals. Philippine J Sci 1925; 28: 11-35.

34. Galliard H, Ngu DV. Une nouvelle espèce d'Eurytrema, E. tonkinense n. sp. parasite du pancréas des bovidés. Ann Parasitol Hum Comp 1941; 18: 187-191 (in French). 


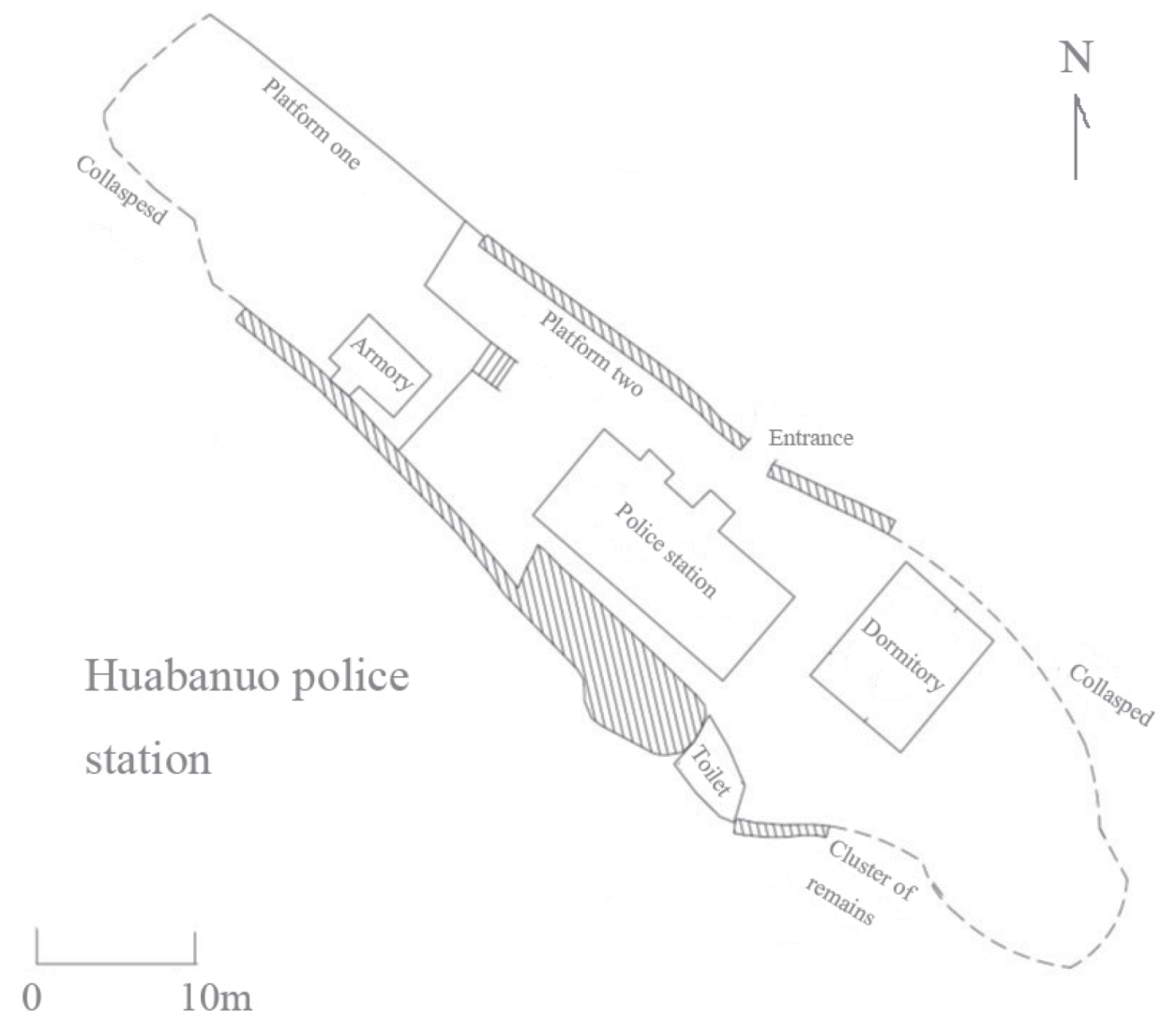

Supplementary Fig. S1. Plan of the Huabanuo police station, giving the location of the toilet. 